J. C. M. Richard

A. Lyazidi

E. Akoumianaki

S. Mortaza

R. L. Cordioli

J. C. Lefebvre

N. Rey

L. Piquilloud

G. F. Sferrazza Papa

A. Mercat

L. Brochard

\section{Erratum to: Potentially harmful effects of inspiratory synchronization during pressure preset ventilation}

Published online: 24 October 2013

(C) Springer-Verlag Berlin Heidelberg and ESICM 2013

The online version of the original article can be found under doi:10.1007/s00134-013-3032-7.

J. C. M. Richard ( $)$ A. Lyazidi · E. Akoumianaki ·

R. L. Cordioli · J. C. Lefebvre - N. Rey - G. F. Sferrazza Papa · L. Brochard

Intensive Care Unit, University Hospital of Geneva,

4 Rue Gabrielle Perret-Gentil, 1211 Genève 14, Switzerland

e-mail: jcmb.richard@gmail.com

J. C. M. Richard · A. Lyazidi · L. Brochard

School of Medicine, University of Geneva, Geneva, Switzerland

S. Mortaza $\cdot$ L. Piquilloud · A. Mercat

Intensive Care Unit, University Hospital of Angers, Angers, France

R. L. Cordioli

Hospital Israelita Albert Einstein, São Paulo, Brazil

J. C. M. Richard

UPRESS EA 38 30, Hôpital Universitaire, de Rouen, Rouen,

France

L. Brochard

INSERM Unit 955, Team 13, University Paris-Est, Créteil, France

\section{Erratum to: Intensive Care Med}

\section{DOI 10.1007/s00134-013-3032-7}

The surname of the ninth author was incorrectly given as Sferrazza-Papa. His correct surname is Sferrazza Papa, with no hyphen. 